$\mathrm{DE}$

M E D I C I N A

T R O P I C A L

$\mathrm{DE}$

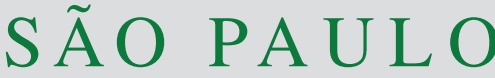

JOURNAL OF THE SÃO PAULO INSTITUTE OF TROPICAL MEDICINE

${ }^{1}$ Universidade de São Paulo, Faculdade de Medicina, Instituto de Medicina Tropical de São Paulo, Laboratório de Imunopatologia da Esquistossomose (LIM-06), São Paulo, São Paulo, Brazil

${ }^{2}$ Universidade de São Paulo, Faculdade de Medicina, Instituto de Medicina Tropical de São Paulo, Laboratório de Gastroenterologia e Hepatologia Tropical (LIM-07), São Paulo, São Paulo, Brazil

${ }^{3}$ Universidade de São Paulo, Faculdade de Medicina, Hospital das Clínicas, Seção de Parasitologia, Divisão do Laboratório Central, São Paulo, São Paulo, Brazil

Correspondence to: Gessica Baptista de Melo

Universidade de São Paulo, Faculdade de Medicina, Instituto de Medicina Tropical de São Paulo, Laboratório de Imunopatologia da Esquistossomose (LIM-06),

Av. Dr. Enéas de Carvalho Aguiar, 470, CEP 05403-000, São Paulo, SP, Brazil Tel: +551130618220

E-mail: gessicamelo@ hotmail.com

Received: 20 December 2019

Accepted: 1 July 2020

\section{Culture isolation and molecular identification of Blastocystis sp. in Brazilian human isolates: preliminary results}

\author{
Gessica Baptista de Melo ${ }^{(1)}$, William Roldan ${ }^{1}$, Fernanda de Mello Malta ${ }^{2}$, \\ Susana Angelica Zevallos Lescano', Vera Lúcia Castilho ${ }^{3}$, Elenice Messias \\ do Nascimento Gonçalves ${ }^{3}$, Fabiana Martins de Paula ${ }^{1}$, Ronaldo Cesar \\ Borges Gryschek ${ }^{1}$
}

\section{ABSTRACT}

Blastocystis sp. is a protist commonly found in stool samples of humans and animals. Biological and genetic factors of this organism remain controversial. The present study aimed to develop and implement the Blastocystis in vitro culture of Brazilian human isolates for routine use. The fecal isolates $(n=20)$ were maintained in our laboratory by several passages in Pavlova's medium. Cultures were monitored every $72 \mathrm{~h}$ by light microscopy. Genomic DNA was extracted to identify the subtypes (STs). In most isolates, the vacuolar form was prevalent. The amoeboid, granular and cystic forms were observed during in vitro cultivation. STs 1, 2, 3, 4 and 7 were identified. Our preliminary results show the generation time and forms present in the in vitro culture of Blastocystis subtypes isolated from Brazilian human isolates. Therefore, we emphasize the use of in vitro culture as a tool in future studies for the better understanding of the biological aspects of Blastocystis sp.

KEYWORDS: Blastocystis sp. In vitro culture. Subtypes. Brazil.

Blastocystis sp. is a unicellular protist that colonizes the intestinal tract of humans and is commonly found in stool samples in clinical laboratories ${ }^{1,2}$. Currently, studies based on the phylogenetic analysis of partial sequences of the ribosomal region (SSU-rDNA) classify Blastocystis sp. as a member of the Stramenopiles phylum ${ }^{3,4}$. The relationship between this organism and clinical manifestations in humans has been controversial until now ${ }^{1,2}$.

Over the years, the number of studies on biological and genetic factors of Blastocystis sp. has increased ${ }^{5-7}$. In vitro culture has been evaluated as a method for the sensitive diagnosis of Blastocystis infections ${ }^{1,8,9}$. In vitro culture has been shown to be two to five-fold more sensitive than standard smears and formalin-ethyl acetate concentration ${ }^{8}$ that allows the parasite purification from fecal debris. The latter can negatively influence the molecular analysis, preventing its application in the clinical diagnosis of Blastocystis sp. ${ }^{9}$. In Brazil, studies have used in vitro culture of Blastocystis sp. as a parasitological diagnostic method ${ }^{10,11}$ and as a method for molecular typing ${ }^{12-14}$ but has not been reported as a tool for biological evaluations. The present study aimed to develop and implement in the clinical laboratory routine, the in vitro culture of Blastocystis from Brazilian human isolates to evaluate the generation time and the forms present in the culture, and to identify the subtypes in the isolates.

The isolates were obtained from 20 fecal samples that yield positive results for Blastocystis sp. according to microscopic examinations held at the Section of Parasitology, Central Laboratory Division (HC/FMUSP), using the Faust, Lutz 
and permanent-stained smears methods ${ }^{15}$. All the isolates were obtained from fresh fecal samples of asymptomatic patients. All the procedures performed in this study were in accordance with the ethical standards (protocol $\mathrm{N}^{\circ} 488-701$ ) of the Ethical Committee of the Hospital das Clinicas da Faculdade de Medicina, Universidade de Sao Paulo, Brazil (HC/FMUSP). The samples were divided into two portions: one portion was cultured on the same day of collection and the other portion was stored at $-20{ }^{\circ} \mathrm{C}$ for molecular analyses.

For the in vitro culture, approximately $200 \mathrm{mg}$ of fecal samples containing a few forms $(<5$ cells per field, x 400 magnification) and containing numerous forms (> 5 cells per field, $x 400$ magnification) were inoculated into 2-mL tubes containing Pavlova's medium ${ }^{16}$ with $12 \mathrm{mg} / \mathrm{mL}$ ampicillin, $4 \mathrm{mg} / \mathrm{mL}$ streptomycin and $10 \%$ inactivated $\left(50^{\circ} \mathrm{C}\right.$ for $\left.50 \mathrm{~min}\right)$ human serum. The culture tubes were incubated at $37^{\circ} \mathrm{C}$ under anaerobic conditions. Blastocystis cultures were monitored every $72 \mathrm{~h}$ by light microscopy. Ten microliters of the culture were collected and Blastocystis forms were counted at x 400 magnification. Cultures were considered negative when Blastocystis sp. forms were not observed after $72 \mathrm{~h}$. If Blastocystis sp. forms were detected, one aliquot of the culture was subcultured in fresh medium and the remaining was stored at $-20{ }^{\circ} \mathrm{C}$ for molecular analyses. In addition, cell growth and viability, the type and number of Blastocystis forms, and the presence or absence of yeasts and bacteria before and during the subculture were evaluated.

For molecular analyses, DNA was extracted from the isolates obtained after $72 \mathrm{~h}$ of cultivation (exponential growth period) of fresh fecal samples, and from isolates recovered after more prolonged periods of in vitro cultivation, corresponding to the deceleration (reduction of cell division) and decline (initiation of cell lysis) periods. Genomic DNA of Blastocystis sp. was obtained using a QIAamp $^{\circledR}$ DNA Stool Mini Kit (QIAGEN Inc., Hilden, Germany) according to the manufacturer's instructions. To determine the subtypes and alleles of Blastocystis sp., a fragment of approximately $600 \mathrm{bp}$, located at the $S S U$-rDNA, was amplified as described by Scicluna et al. ${ }^{17}$. PCR was performed following the protocol described by Melo et al. ${ }^{18}$. The amplification products were identified in $2 \%$ agarose gel electrophoresis with the addition of SYBR safe (Invitrogen ${ }^{\mathrm{TM}}$, Thermo Fisher Scientific Corporation, Waltham, MA, USA).

Both strands of the amplicons were sequenced using the ABI PRISM ${ }^{\circledR}$ BigDye $^{\mathrm{TM}}$ Terminator kit (Applied Biosystems, Thermo Fisher Scientific Corporation, Waltham, USA), according to Sanger et al. ${ }^{19}$ sequencing method. To determine the subtype and alleles of each sample, Blastocystis sp. sequences retrieved from the NCBI website using the BLASTn tool ${ }^{20}$ and Blastocystis subtypes (18S) sequence typing ${ }^{21}$ were aligned and compared with the sequences obtained in this study. The sequences were deposited in the GenBank database under the accession numbers MK511783-MK511793.

The in vitro culture can be used to identify Blastocystis sp. from fecal samples, mainly to facilitate the morphological discrimination, and has an excellent diagnostic performance compared with conventional microscopy ${ }^{9}$. However, many other biological aspects remain unexplored and a possible explanation is the lack of an adequate experimental model, that has not yet been well established for Blastocystis. In this context, the in vitro culture can be a promising tool for a better understanding of these aspects, such as antigen and antibody production, host-parasite interactions and strain differences ${ }^{2,6,22}$.

The presence of a large number of forms was observed in the growing period of in vitro cultivation (exponential growth period), as already described in the literature ${ }^{7,9}$. Of the 20 isolates subjected to culture, 16 were maintained for up to $72 \mathrm{~h}$. In our isolates, vacuolar, granular, amoeboid, cystic, multivacuolar and avacuolar forms were detected. In most isolates, the vacuolar form was the most prevalent form in the exponential growth period (Figure 1). The vacuolar form has been considered the typical Blastocystis cell form and the predominant form of the organism in culture ${ }^{6-8}$, mainly in short-term in vitro cultivation ${ }^{9}$. In this study, the granular form was observed after $72 \mathrm{~h}$ but was not observed in the decline period. While the cultures were maintained, the amoeboid, granular and cystic forms were observed. Zhang et al. ${ }^{22}$ described cysts in long-term cultures. In addition, the amoeboid forms have rarely been reported in cultures, mainly in fecal samples from symptomatic patients ${ }^{6}$, however, only one isolate (IS05) was described.

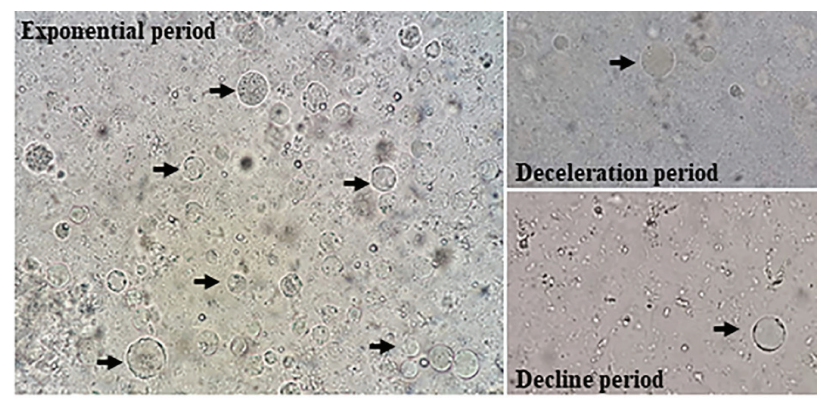

Figure 1 - Light microscopy images of the morphological forms of Blastocystis sp. observed in the exponential, deceleration and decline periods of in vitro cultivation. High-powered field (× 400 magnification).

In this study, the cultures were monitored for four months. The mean duration of in vitro cultures was 31.5 days (median, 
17 days). Some studies have reported that the growth time of Blastocystis cultures may vary accordimg to the culture conditions $^{7}$, and among different subtypes ${ }^{23}$. According to Irikov et al. ${ }^{7}$, the maximum Blastocystis cell count occurs between 3 and 5 days of culture. In the present study, the exponential period occurred between 3 to 6 days of culture, and the deceleration period began after 10 days in most cultures. During the decline period, yeast cells were observed. Some studies suggest the use of antibiotic and anti-fungi cocktails to eliminate potential contamination by bacteria or yeast, but this does not guarantee the successful elimination of contaminants or the culture survival ${ }^{6}$.

The cultures with the highest viability were obtained from the following isolates: IS05 (72 days), IS15 (130 days) and IS16 (34 days). They contained the largest number of forms, mainly granular forms. Although the cultivation period in this study was four months, isolate IS15 was still maintained in culture after 130 days.

Of the 16 isolates that were maintained for at least 72 h, only 14 had results confirmed by PCR, reinforcing the applicability of the culture as a diagnostic tool. On the contrary, a study by Roberts et al..$^{24}$ found a lower sensitivity of culture compared with PCR. In our analysis of the 14 PCR products, 11 were successfully sequenced and three samples were excluded due to the low-quality of sequences These findings are in accordance with the literature ${ }^{13,14}$. Table 1 details the morphological and molecular characterization of isolates cultivated in vitro.

Subtypes 1 (27.3\%), 2 (9.1\%), 3 (27.3\%), 4 (27.3\%), and $7(9.1 \%)$ were identified by molecular analysis (Table 1$)$.

Table 1 - Morphological characterization during in vitro cultivation in the exponential (after $72 \mathrm{~h}$ of cultivation), deceleration (reduction of cell division) and decline (initiation of cell lysis) periods, and molecular identification of Brazilian-human isolates of Blastocystis.

\begin{tabular}{|c|c|c|c|c|c|c|c|c|c|c|}
\hline \multirow[b]{2}{*}{ Isolate (IS) } & \multirow{2}{*}{$\begin{array}{c}\text { Blastocystis } \\
\text { forms } \\
\text { inoculated }\end{array}$} & \multicolumn{3}{|c|}{ Type of Blastocystis forms } & \multirow{2}{*}{$\begin{array}{c}\text { Mean number } \\
\text { of Blastocystis } \\
\text { forms }\end{array}$} & \multirow{2}{*}{$\begin{array}{l}\text { Total period } \\
\text { of in vitro } \\
\text { maintenance } \\
\text { (days) }\end{array}$} & \multirow{2}{*}{$\begin{array}{c}\text { Similarity } \\
(\%)\end{array}$} & \multirow[b]{2}{*}{ Subtype } & \multirow[b]{2}{*}{ Alleles } & \multirow{2}{*}{$\begin{array}{c}\text { GenBank } \\
\text { Accession } \\
\text { number }\end{array}$} \\
\hline & & $\begin{array}{l}\text { Exponential } \\
\text { period }\end{array}$ & $\begin{array}{c}\text { Deceleration } \\
\text { period }\end{array}$ & $\begin{array}{l}\text { Decline } \\
\text { period }\end{array}$ & & & & & & \\
\hline IS1 & $\mathrm{N}$ & $\begin{array}{l}\text { Vacuolar, } \\
\text { amoeboid, } \\
\text { binary division }\end{array}$ & $\begin{array}{l}\text { Vacuolar, } \\
\text { amoeboid, } \\
\text { cysts, }\end{array}$ & $\begin{array}{c}\text { Vacuolar, } \\
\text { avacuolar, } \\
\text { yeast }\end{array}$ & $2 \times 10^{6}$ & 21 & $99.14-100$ & 3 & 37 & MK511783 \\
\hline IS2 & $\mathrm{F}$ & $\begin{array}{c}\text { Vacuolar, } \\
\text { avacuolar, } \\
\text { binary division }\end{array}$ & $\begin{array}{c}\text { Vacuolar, } \\
\text { avacuolar, } \\
\text { multivacuolar }\end{array}$ & $\begin{array}{c}\text { Vacuolar, } \\
\text { avacuolar, } \\
\text { yeast }\end{array}$ & $10^{6}$ & 21 & $99.48-100$ & 3 & 36 & MK511784 \\
\hline IS3 & $\mathrm{F}$ & $\begin{array}{c}\text { Vacuolar, } \\
\text { avacuolar, } \\
\text { binary division }\end{array}$ & Vacuolar & $\begin{array}{c}\text { Vacuolar, } \\
\text { yeast }\end{array}$ & $6 \times 10^{5}$ & 17 & $98.65-100$ & 1 & 4 & MK511785 \\
\hline IS4 & $\mathrm{F}$ & $\begin{array}{c}\text { Vacuolar, } \\
\text { avacuolar, } \\
\text { binary division }\end{array}$ & Vacuolar & $\begin{array}{c}\text { Vacuolar, } \\
\text { yeast }\end{array}$ & $10^{6}$ & 15 & $99.00-100$ & 3 & 34 & MK511786 \\
\hline IS5 & $\mathrm{F}$ & $\begin{array}{c}\text { Vacuolar, } \\
\text { granular, } \\
\text { binary division }\end{array}$ & $\begin{array}{l}\text { Vacuolar, } \\
\text { granular, } \\
\text { amoeboid, } \\
\text { cysts }\end{array}$ & $\begin{array}{c}\text { Vacuolar, } \\
\text { yeast }\end{array}$ & $4 \times 10^{6}$ & 72 & $98.33-100$ & 4 & 42 & MK511787 \\
\hline IS7 & $\mathrm{F}$ & Vacuolar & Vacuolar & $\begin{array}{c}\text { Vacuolar, } \\
\text { yeast }\end{array}$ & $4 \times 10^{5}$ & 6 & 99.35 & 4 & 42 & MK511788 \\
\hline IS8 & $\mathrm{N}$ & Vacuolar & Vacuolar & $\begin{array}{c}\text { Vacuolar, } \\
\text { yeast }\end{array}$ & $4 \times 10^{5}$ & 6 & 99.35 & 4 & 42 & MK511789 \\
\hline IS11 & $\mathrm{F}$ & Vacuolar & Vacuolar & $\begin{array}{c}\text { Vacuolar, } \\
\text { yeast }\end{array}$ & $6 \times 10^{5}$ & 16 & $98.51-100$ & 1 & 4 & MK511790 \\
\hline IS12 & $\mathrm{N}$ & $\begin{array}{c}\text { Vacuolar, } \\
\text { granular, } \\
\text { binary division }\end{array}$ & $\begin{array}{l}\text { Vacuolar, } \\
\text { granular }\end{array}$ & Vacuolar & $2 \times 10^{6}$ & 9 & $95.83-100$ & 7 & 99 & MK511791 \\
\hline IS15 & $\mathrm{N}$ & $\begin{array}{l}\text { Vacuolar, } \\
\text { granular, } \\
\text { binary division }\end{array}$ & $\begin{array}{l}\text { Vacuolar, } \\
\text { granular, } \\
\text { cysts, } \\
\text { schizogony }\end{array}$ & $\begin{array}{l}\text { Vacuolar, } \\
\text { granular }\end{array}$ & $2 \times 10^{6}$ & 130 & $97.85-99.83$ & 2 & 12 & MK511792 \\
\hline IS16 & $\mathrm{F}$ & $\begin{array}{c}\text { Vacuolar, } \\
\text { granular, } \\
\text { binary division }\end{array}$ & $\begin{array}{l}\text { Vacuolar, } \\
\text { granular }\end{array}$ & Vacuolar & $4 \times 10^{5}$ & 34 & $98.65-100$ & 1 & 4 & MK511793 \\
\hline
\end{tabular}

$\mathrm{F}=$ few forms $(<5$ cells per field; $x 400$ magnification); $N=$ numerous forms ( $>5$ cells per field; $x 400$ magnification). 
The comparison of the sequences with reference ones described previously showed a similarity ranging from $95.83 \%$ to $100 \%$. The allele assignment was obtained for all the sequences. For ST1 and ST4, all the sequences were classified as alleles 4 and 42, respectively. For ST3, three alleles were detected (34, 36 and 37), for ST2 (allele 12) and ST7 (allele 99). Variable alleles occurring within subtypes of Blastocystis in a given population are common ${ }^{25}$.

Subtypes 1 (IS16) and 2 (IS15) were successfully maintained in vitro for 34 to 130 days, demonstrating that they were adapted to the culture conditions. In addition, we observed a shorter maintenance time of some isolates (IS7, IS8 and IS12) belonging to subtypes 4 and 7, that were maintained in vitro for 6 to 9 days. Furthermore, amoeboid forms were observed in IS05 (subtype 4), a characteristic that has been associated with the possible pathogenicity of Blastocystis sp.

Our findings show preliminary results involving the generation time and type of forms present in vitro during the maintenance of Blastocystis subtypes isolated in Brazil. Therefore, in vitro culture can be used as a tool in future studies, including a larger number of samples and clinical data, which will help the understanding of biological aspects of the Blastocystis sp.

\section{ACKNOWLEDGMENTS}

This study was supported by grants from the Fundação de Amparo à Pesquisa do Estado de São Paulo (FAPESP grant N $^{\circ}$ 2015/18213-6) and Coordenação de Aperfeiçoamento de Pessoa de Nível Superior (CAPES grant N ${ }^{\circ} 1749729$ ).

\section{CONFLICT OF INTERESTS}

The authors declare no conflicts of interest.

\section{REFERENCES}

1. Coyle CM, Varughese J, Weiss LM, Tanowitz HB. Blastocystis: to treat or not to treat. Clin Infect Dis. 2012;54:105-10.

2. Andersen LO, Stensvold CR. Blastocystis in health and disease: are we moving from a clinical to a public health perspective? J Clin Microbiol. 2016;54:524-8.

3. Silberman JD, Sogin ML, Leipe DD, Clark CG. Human parasite finds taxonomic home. Nature. 1996;380:398.

4. Arisue N, Hashimoto T, Yoshikawa H, Nakamura Y, Nakamura G, Nakamura F, et al. Phylogenetic position of Blastocystis hominis and of Stramenopiles inferred from multiple molecular sequence data. J Eukaryot Microbiol. 2002;49:42-53.

5. Stensvold CR, Arendrup MC, Jespersgaard C, Mølbak K, Nielsen HV. Detecting Blastocystis using parasitologic and DNA-based methods: a comparative study. Diagn Microbiol Infect Dis. 2007;59:303-7.

6. Tan KS. New insights on classification, identification, and clinical relevance of Blastocystis spp. Clin Microbiol Rev. 2008;21:639-65.

7. Irikov OA, Antokhin AI, Romanov YA. Study of the dynamics of Blastocystis hominis reproduction in vitro. Bull Exp Biol Med. 2009;148:99-102.

8. Leelayoova S, Taamasri P, Rangsin R, Naaglor T, Thathaisong $\mathrm{U}$, Mungthin M. In-vitro cultivation: a sensitive method for detecting Blastocystis hominis. Ann Trop Med Parasitol. 2002;96:803-7.

9. Zhang X, Qiao J, Wu X, Da R, Zhao L, Wei Z. In vitro culture of Blastocystis hominis in three liquid media and its usefulness in the diagnosis of blastocystosis. Int J Infect Dis. 2012;16:e23-8.

10. Valença-Barbosa C, de Jesus Batista R, Pereira Igreja R, d'Avila Levy CM, Werneck de Macedo H, Carneiro Santos HL. Distribution of Blastocystis subtypes isolated from humans from an urban community in Rio de Janeiro, Brazil. Parasit Vectors. 2017;10:518.

11. Barbosa CV, Barreto MM, Andrade RJ, Sodré F, d'Avila Levy CM, Peralta JM, et al. Intestinal parasite infections in a rural community of Rio de Janeiro (Brazil): prevalence and genetic diversity of Blastocystis subtypes. PLoS One. 2018;13:e193860.

12. David EB, Guimarães S, de Oliveira AP, Goulart de OliveiraSiqueira TC, Nogueira Bittencourt G, Moraes Nardi AR, et al. Molecular characterization of intestinal protozoa in two poor communities in the State of São Paulo, Brazil. Parasit Vectors. 2015;8:103.

13. Seguí R, Muñoz-Antoli C, Klisiowicz DR, Oishi CY, Köster PC, de Lucio A, et al. Prevalence of intestinal parasites, with emphasis on the molecular epidemiology of Giardia duodenalis and Blastocystis sp., in the Paranaguá Bay, Brazil: a community survey. Parasit Vectors. 2018;11:490.

14. Oliveira-Arbex AP, David EB, Guimarães S. Blastocystis genetic diversity among children of low-income daycare center in Southeastern Brazil. Infect Genet Evol. 2018; 57:59-63.

15. Garcia LS. Diagnostic medical parasitology. $4^{\text {th }}$ ed. Washington, DC: ASM Press; 2001.

16. Zerpa R, Huicho L, Náquira C, Espinoza I. A simplified culture method for Blastocystis hominis. Rev Mex Patol Clin. 2000;47:17-19.

17. Scicluna SM, Tawari B, Clark CG. DNA barcoding of Blastocystis. Protist. 2006; 157:77-85.

18. Melo GB, Paula FM, Malta FM, Maruta CW, Criado PR, Castilho VL, et al. Identification of Blastocystis subtypes in clinical stool samples from Sao Paulo City, Brazil. Parasitol Open. 2017;3:e3

19. Sanger F, Nicklen S, Coulson, AR. DNA sequencing with 
chain-terminating inhibitors. Proc Natl Acad Sci U S A. 1977;74:5463-7.

20. National Center for Biotechnology Information. What is tbl2asn? [cited $2020 \mathrm{Jul}$ 1]. Available from: http://www.ncbi.nlm.nih. gov/GenBank/tbl2asn2

21. University of Oxford. Blastocystis subtype (18S) and sequence typing (MLST) databases. [cited 2020 Jul 1]. Available from: http://pubmlst.org/blastocystis/

22. Zhang X, Qiao JY, Zhou XJ, Yao FR, Wei ZC. Morphology and reproductive mode of Blastocystis hominis in diarrhea and in vitro. Parasitol Res. 2007;101:43-51.
23. Parija SC, Jeremiah S. Blastocystis: taxonomy, biology and virulence. Trop Parasitol. 2013;3:17-25.

24. Roberts T, Barratt J, Harkness J, Ellis J, Stark D. Comparison of microscopy, culture, and conventional polymerase chain reaction for detection of Blastocystis sp. in clinical stool samples. Am J Trop Med Hyg. 2011;84:308-12.

25. Jiménez PA, Jaimes JE, Ramírez JD. A summary of Blastocystis subtypes in North and South America. Parasit Vectors. 2019;12:376. 